\title{
Current evidence on the effectiveness of systemic herbal medicine for psoriasis: A systematic review with meta- analysis
}

Tony Yuqi Tangi*, Fangzhou Li ${ }^{2}$, Andrew Affleck ${ }^{3}$, Jayne Donaldson ${ }^{4}$ and Zoe Chouliara ${ }^{4}$

${ }^{1}$ Herose Clinical Centre, 190 Clemenceau Ave, \#03-24, SSC, Singapore

${ }^{2}$ Department of Law, School of Humanities, Inner Mongolia University of Technology, China

${ }^{3}$ Department of Dermatology, Ninewells Hospital, Dundee, United Kingdom

${ }^{4}$ School of Nursing, Midwifery and Social Care, Faculty of Health, Life and Social Sciences, Edinburgh Napier University, Scotland

\begin{abstract}
Herbal medicines have been used to treat psoriasis for many years with anecdotal reports of efficacy which have attracted public attention. We seek to assess the effects of systemic herbal medicine in the treatment of psoriasis. Medical database PubMed/MEDLINE, AMED, CINAHL, and CENTRAL were searched. Randomised controlled trials of systemic herbal medicine used in the treatment of psoriasis included in the meta-analysis. Two reviewers independently applied eligibility criteria, assessed the quality of the trials and extracted data. Any discrepancies were discussed with additional reviewer to achieve consensus. Nine randomised controlled trials met the inclusion criteria. The trials randomised 785 participants. Three RCTs revealed that herbal medicine performed better than placebo control (RR=3.98, 1.36$11.62,95 \% \mathrm{CI}, \mathrm{I} 2=68 \%, \mathrm{p}=0.01)$, four $\mathrm{RCT}$ s demonstrated that the western drug competitor is superior to herbal medicine $(\mathrm{RR}=0.73,0.53-0.97,95 \% \mathrm{CI}, \mathrm{I} 2=52 \%$, $\mathrm{p}=0.03$ ), two RCTs suggested that herbal medicine combined with other medication, (i.e. Auricular Acupuncture or Acitretin (a systemic retinoid), is more effective than herbal medicine alone $(\mathrm{RR}=1.92,1.28-2.88,95 \% \mathrm{CI}, \mathrm{I} 2=0 \%, \mathrm{p}=0.002)$. The results of one $\mathrm{RCT}$ indicated that herbal medicine reduced the occurrence of adverse reactions of Acitretin, when it was used in combination with herbal medicine. The findings are not conclusive due to the high risk of bias of the included trials and the limited number of trials testing individual herbal medicines. Further well-designed larger scale trials are required to determine the safety and efficacy of oral herbal interventions in the treatment of psoriasis.
\end{abstract}

\section{Introduction}

Psoriasis is a common, chronic, and recurrent inflammatory disease of the skin [1-3]. Worldwide psoriasis prevalence rates range from 0.6 percent to 4.8 percent [4]. Prevalence is higher in European $1.5 \%-3.5 \%[5,6]$ compared with $0.1 \%-0.3 \%$ in the Far East and China [6,7]. Psoriasis impacts on daily living activities and may cause a financial burden on affected individuals [8-12]. A population-based survey conducted by Stern et al. [13] showed that $60 \%$ ( $\mathrm{n}=4.5 \mathrm{million})$ of patients report the disease affects their everyday life and $26 \%(n=4.5$ million) report a change or discontinuation of their daily activities. In the United States, total direct and indirect cost of psoriasis is estimated at 11.25 billion dollars annually, national direct medical costs increased from 650 million to 4.3 billion dollars over 6 years time period $[8,11]$. The cause of psoriasis is genetic with multiple inherited and acquired factors interacting [14].

Conventional treatment options focus on symptomatic management and may be associated with unwanted side effects and the development of drug tolerance [15-17]. Herbal medicine has been used as medicine for thousands of years [18], for example, saw palmetto was used for urinary symptoms in ancient Egypt [19], and a Chinese classic book named Inner Classic of the Yellow Emperor describes traditional Chinese herbs on skin diseases [20]. Herbal medicines are popular in America: in the 19th century, around two-thirds of medicine listed in the first edition of the United States Pharmacopoeia USP published in 1820 was botanical substances [21-23]. Fermentation products and highly purified or chemically modified botanical substances are not considered as botanical drug by FDA.

It is reported that in the China and USA around $43 \%-69 \%$ of patients inquire about traditional medicine (Herbal medicine, Traditional Chinese Medicine TCM, complementary alternative medicine CAM) to seek long-term psoriasis remission without side effects [24-29]. Studies have shown that some herbal medicines may be effective for psoriasis [30-33]. There were some alternative and complementary medicine CAM for psoriasis treatment reviews published previously [6,32,34-36], but literature reviews based on evidence from randomised control trials on systemic herbal intervention are rare.

Due to lack of standard clinical practice on systemic herbal medication and a knowledge gap in regards of evidence-based medicinal use of systemic herbal medicine in psoriasis patients, the following two research questions were constructed:

Correspondence to: Dr. Tony Yuqi Tang, Herose Clinical Centre, 190 Clemenceau Ave, \#03-24, SSC, Singapore 239924, Tel: (65) 63334066; Fax: (65) 63339654; E-mail: fbap8143@gmail.com

Key words: psoriasis, herbal medicine, Chinese medicine, plant medicine, oriental medicine, kampo medicine, complementary medicine, alternative medicine, botanical drug

Received: March 06, 2015; Accepted: April 28, 2015; Published: May 04, 2015 


\section{The primary aims:}

1. What, if any, evidence from randomized controlled trials (RCTs) exists for treatment of psoriasis with systemic herbal medicine?

2. What is the quality of the evidence for published systemic herbal medicine RCTs on psoriasis?

In order to answer these clinical questions, a systematic literature review was undertaken to evaluate the published RCTs on the safety and efficacy of treatment of psoriasis with systemic herbal medicine compared with placebo or comparator or herbal medicine +/- western medicine. The objectives of this review are to:

1. Identify and examine the safety and efficacy of herbal systemic intervention in the treatment of psoriasis

2. Critically appraise and summarise the available literature relating to systemic herbal therapy in psoriasis patients

3. Provide physicians and patients with up-to-date evidencebased recommendations of systemic herbal medicine for psoriasis.

The findings of the examined randomized controlled trials will be analysed.

\section{Methods}

We conducted a systematic review on the efficacy and safety of systemic herbal treatments for psoriasis.

\section{Database and search strategies}

The query search using patient characteristics, type of intervention, control, and outcome PICO format [35] was used to facilitate the literature searching process. MEDLINE/PubMed via PICO (http://pubmedhh.nlm.nih.gov/nlmd/pico/piconew.php)search provided by National Library of Medicine is applied as a primary search strategy in this paper. In PICO (patient, intervention, control, and outcome) category searching, "psoriasis" is used in patient category, keywords and synonyms "herbal medicine", "Chinese medicine", "plant medicine", "oriental medicine", "kampo medicine", "complementary medicine", "alternative medicine" and "botanical drug" are used in intervention category, control and outcome category leave in blank. Publication type is selected as "clinical trial" and "review". The relevant reference of review articles generated by PICO searching and reference of the references in the related literatures are also searched and retrieved.

Electronic searches were conducted on the following databases: PubMed/MEDLINE, AMED (Allied and Complimentary Medicine), CINAHL, and Cochrane Central Register of Controlled Trials (CENTRAL). The search terms were a combination of Medical Subject Heading MeSh terms and their synonyms.A combination of MeSH terms and synonyms in PubMed/Medline, is listed in Table 1.

\section{Inclusion/exclusion criteria}

\section{Inclusion criteria}

- The research participants to be included in this review are patients who are clinically diagnosed with psoriasis or psoriatic arthritis.

- Placebo, no treatment or competitor medicine treatment as control interventions.
Table 1. Literature search in PubMed/Medline.

\begin{tabular}{|l|l|l|l|}
\hline No. & Search term & Search syntax & $\begin{array}{l}\text { Hits on 11 } \\
\text { July 2013 }\end{array}$ \\
\hline 1 & Randomized controlled trial & Publication type & 435,264 \\
\hline 2 & Randomized controlled trial as topic & MeSH & 116,520 \\
\hline 3 & Psoriasis & MeSH & 34,292 \\
\hline 4 & Chinese medicine & MeSH & 70,661 \\
\hline 5 & Herbal medicine & MeSH & 21,078 \\
\hline 6 & Traditional medicine & MeSH & 68,902 \\
\hline 7 & Phytotherapy & MeSH & 28,072 \\
\hline 8 & Botanical drug & MeSH & 1,575 \\
\hline 9 & Oriental medicine & MeSH & 16,104 \\
\hline 10 & Alternative medicine & MeSH & 218,695 \\
\hline 11 & Complementary medicine & MeSH & 192,255 \\
\hline 12 & Kampo medicine & MeSH & 878 \\
\hline 13 & Term 1 or 2 & & 435,264 \\
\hline 14 & Term 4 or 5 or 6 or 7 or 8 or 9 or 10 or 11 or 12 & & 323,908 \\
\hline 15 & Term 3 and 13 and 14 & & 42 \\
\hline & & & \\
\hline
\end{tabular}

- No age limit was set.

- Only randomized controlled trials articles will be included in the analysis.

- Intervention was any herbal medicine or combination of herbal medicines administered for systemic effect for psoriasis where herbal medicine(s) could be described as vegetable materials, which may include plant materials, algae, macroscopic fungi, combinations thereof, or may derived from plants or parts of plants i.e. leaves, stems, buds, flowers, roots or tubers.

- Limits were set for publication within 11 years (Jan 2002 to Jan 2013). The Consolidated Standards of Reporting Trials (CONSORT) Statement was first published in 1996 [39] as a clinical trial reporting guideline. The revised CONSORT Statement was published in 2001 and endorsed by three prestigious international medical journals, The Journal of the American Medical Association, Lancet and Annals of Internal Medicine. Therefore reviewers choose the clinical studies on psoriasis published since 2002 .

\section{Exclusion criteria}

Articles excluded if:

- It is not published in the English language due to time constraints;

- It does not use "randomization";

- It does not have the primary end point as a clinical assessment;

- It contained interventions that used non-herbal therapies (vitamin, mineral supplements, fish oils, spa therapy, psychotherapy, acupuncture etc.);

- It used topical herbal therapies (ointment, cream, lotion etc.);

- It used therapies using plant-derived chemicals or synthetic chemicals that contain constituents of plants.

\section{Analytic framework}

Once the literature search was complete, two reviewers (T.Y.T and F.L) independently conducted the selection and data extraction. Any discrepancies were resolved by additional reviewer (J.D). 
From the list of included studies, the identified literature were appraised and assessed for methodological quality by using CONSORT Statement for Herbal Interventions [40] and for the risk of bias by using Cochrane Collaboration's tool [41] for assessing risk of bias.

\section{Data analysis}

Data were analysed and the meta-analysis were conducted in statistical software RevMan5 that was provided by The Cochrane Collaboration IMS. Dichotomous data were presented as risk ratio RR Mantel-Haenszel method with a 95\% confidence interval 95\%CI. Metaanalysis was performed if the intervention, control and outcome were all the similar. The statistical heterogeneity was presented as significant when $\mathrm{I}^{2}>50 \%$ or $\mathrm{P}<0.1$.

\section{Findings}

\section{Study selection}

Literature search in PubMed/Medline (Table 1) yielded a total of 42 articles, in Cochrane/CENTRAL yielded a total of 49 articles, in CINAHLE/EBSCO host yielded a total of 124 articles, in AMED/ EBSCO host yielded a total of 75 articles respectively. PICO search via

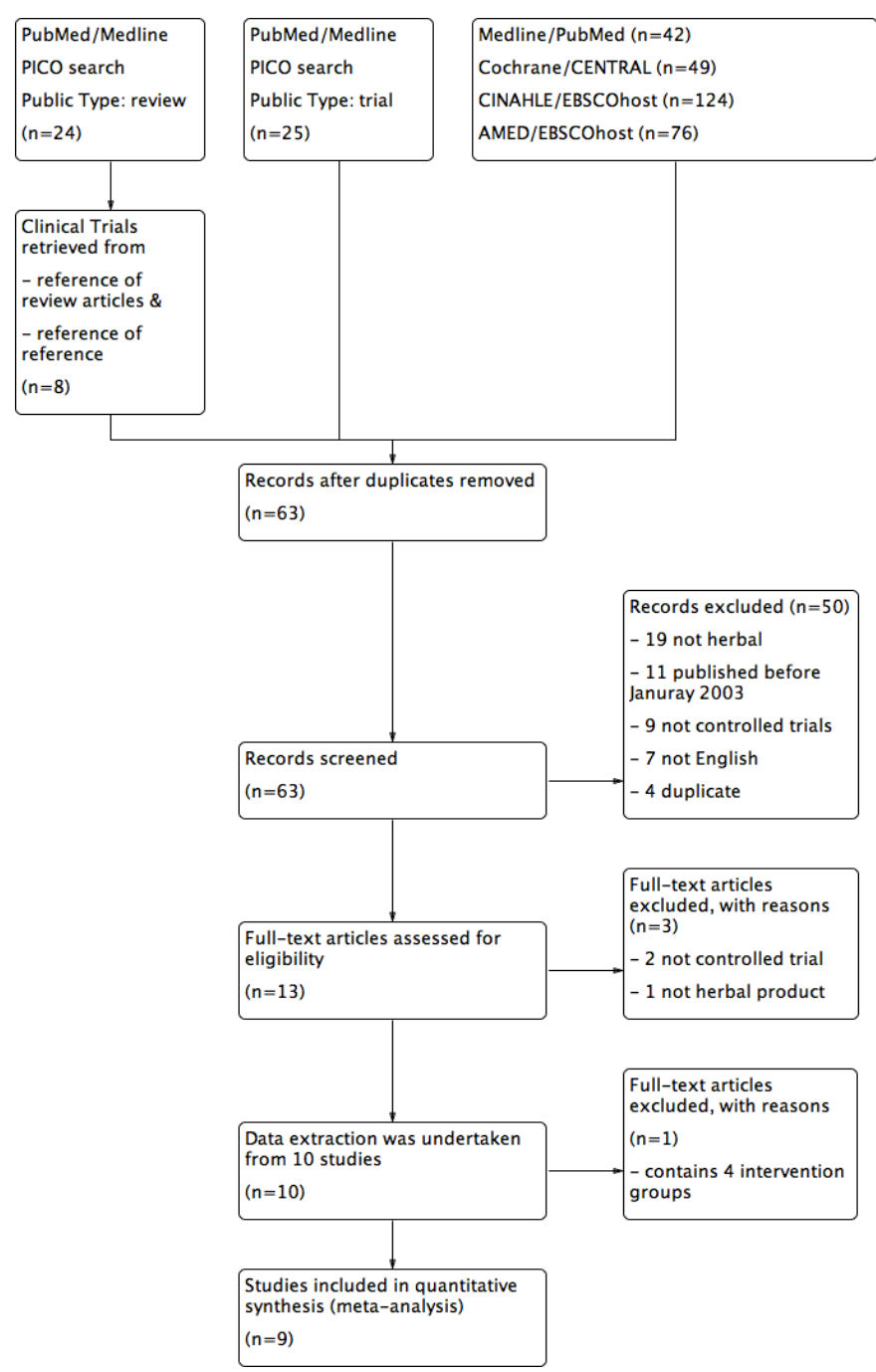

Figure 1. Flow chart of selection of randomised controlled trials (RCTs) of systemic herbal medicines for psoriasis.
PubMed/Medline yield a total of 24 review articles. After screening the reference of review articles, total 8 clinical trials paper were identified. PICO search via PubMed/Medline yield a total of 25 clinical trials papers. After screening titles and abstracts, duplicates, non-herbal studies, non-English articles, non-controlled trials were excluded. A total 63 articles were screened out from electronic database searches. The selection of randomised controlled trials RCTs of herbal medicines for psoriasis is described in Figure 1, a flow diagram using the PRISMA template described in the PRISMA statement [42]. A total 13 full text articles were retrieved for further evaluation, 2 were not a randomised controlled trial, 1 was not a herbal intervention. Data were extracted from the remaining 10 [43-52], Hegazi et al. (2013) [52] study was excluded from the meta-analysis because it contains 4 intervention groups and therefore did not meet the inclusion criteria for this review.

\section{Characteristics of included studies}

The 9 studies from which data were extracted included a total of 785 participants with psoriasis. The studies' characteristics, methods, participants, interventions and outcome are summarized on Table 2.

\section{Clinical efficacy of herbal medicine}

The 9 RCTs [43-51] involved 785 participants are conducted in meta-analysis by using the Cochrane Collaboration's tool Review Manager (RevMan) [Computer program Version 5.2. Copenhagen: The Nordic Cochrane Centre, The Cochrane Collaboration, 2012]. These 9 RCTs were divided into 3 sub-groups according to the measures of intervention used: Group A: 3 RCTs [43,46,48] used herbal as intervention and were controlled using placebo as illustrated in Figure 2. Group B: 4 RCTs [44-47] used herbal as intervention and were controlled using competitor (herbal or western drug) as illustrated in Figure 3. Group C: 2 RCTs [49,51] used herbal medicine in combination with other medicine as intervention and were controlled using herbal product alone as illustrated in Figure 4.

Three studies, Ahmadi et al. [43], Ho et al. [46], Lone et al. [48], included in the subgroup A meta-analysis (Figure 2) and listed in the first column "study or subgroup". The individual study findings are displayed in this subgroup meta-analysis with binary outcomes (herbal intervention/placebo control). For example, in Figure 2, there are 9 out of 14 participants of herbal invention group show treatment efficacy, and there are 0 out of 14 participants of placebo control group show treatment efficacy in Ahmadi et al. [43] study. The influence of each individual study on overall meta-analysis are weighted at $11.5 \%, 73.3 \%$ and $15.1 \%$ by Ahmadi et al. [43], Ho et al. [46] and Lone et al. [48] respectively. The Risk Ratio (RR) effect measure, Mantel-Haenszel (MH) statistical method and the Fixed Effect analysis model with $95 \%$ Confidence Interval used to perform the meta-analysis. Each study is represented by a horizontal line on the forest plot. There is a blue square box in the line for each study. The width of the line shows the confidence intervals of the effect estimate of individual studies. The mid-point of the box represents the point effect estimate, that is, the mean effect estimate for each study. The area of the box represents the weight given to the study. The black diamond shape below the 3 studies represents the overall effect. The width of the diamond shows the confidence intervals for the overall effect estimate. The middle of the diamond sits on the value for the overall effect estimate of the Risk Ratio (RR). There is a vertical line that corresponds to the value 1 in the forest plot. This is the line of no treatment effect. Note also that it says "Favours Placebo" to the left of the vertical line and "Favours Herbal" to the right of the vertical line. On the forest plot shown on Figure 2, the 95\% confidence intervals of the two studies (Ho et al. [46], 
Table 2. Characteristics of included studies.

\begin{tabular}{|c|c|}
\hline \multicolumn{2}{|c|}{ Ahmadi et al. 2008} \\
\hline Methods & $\begin{array}{l}\text { Design: randomised, double-blind, placebo-controlled } \\
\text { Duration: } 6 \text { months trial and } 6 \text { months follow-up } \\
\text { Interval of assessment: every } 4 \text { weeks }\end{array}$ \\
\hline Participants & $\begin{array}{l}\text { Number randomised: } 28 \text { (14 in each group) } \\
\text { Sex }(\mathrm{M} / \mathrm{F}): 5 / 9 \text { in treatment group and } 6 / 8 \text { in placebo groups } \\
\text { Age of participants: Not specified } \\
\text { Country and setting: Iran, single university centre } \\
\text { Inclusion criteria of the study } \\
\text { - Diagnostic criteria: clinical diagnosis of psoriasis vulgaris } \\
\text { Exclusion criteria of the study } \\
\text { - Erythrodermic } \\
\text { - Exfoliative } \\
\text { - Pustular psoriasis } \\
\text { - Skin infections, } \\
\text { - Systemic and/or topical antipsoriatic treatment in the } 8 \text {-week prior to the study, } \\
\text { - PUVA, UVB } \\
\text { - pregnancy or breastfeeding }\end{array}$ \\
\hline Interventions & $\begin{array}{l}\text { - Treatment group: HESA-A tablet } 25 \mathrm{mg} / \mathrm{Kg} \text { BD orally } \\
\text { - Placebo group: Not specified }\end{array}$ \\
\hline Outcomes & $\begin{array}{l}\text { 6-point scale: absent (no evidence of psoriasis), very mild (controlled, but not entirely cleared), mild (lesions of slight redness, thickness and scaliness), moderate } \\
\text { (red lesions with moderate thickness and scaliness), severe (very red lesions with severe thickness and scaliness), and very severe (extremely red lesions with very } \\
\text { severe thickness and scaliness). }\end{array}$ \\
\hline \multicolumn{2}{|l|}{ Notes } \\
\hline \multicolumn{2}{|c|}{ Chang et al. 2006} \\
\hline Methods & $\begin{array}{l}\text { Design: randomised, active comparator-controlled } \\
\text { Duration: } 8 \text { weeks } \\
\text { Interval of assessment: start and end of study }\end{array}$ \\
\hline Participants & $\begin{array}{l}\text { Number randomised: } 120 \text { ( } 60 \text { in each group) } \\
\text { Sex }(\mathrm{M} / \mathrm{F}): 34 / 26 \text { in treatment group and } 31 / 29 \text { in placebo group } \\
\text { Age of participants (mean): } 35.47 \pm 12.5 \text { in treatment group and } 36.40 \pm 11.32 \text { in placebo group } \\
\text { Country and setting: China, single centre } \\
\text { Inclusion criteria of the study } \\
\text { - Diagnostic criteria: Principle for Directing Clinical Studies on New Drugs of Chinese Materia Medica for Treating Psoriasis, MOH, China } \\
\text { - Blood-heat syndrome in traditional Chinese medicine } \\
\text { Exclusion criteria of the study } \\
\text { - Severe cardiovascular } \\
\text { - Cerebrovascular } \\
\text { - Pustular psoriasis } \\
\text { - Hepatic diseases } \\
\text { - Renal diseases } \\
\text { - Mental disorders } \\
\text { - Women in pregnancy or breastfeeding }\end{array}$ \\
\hline Interventions & $\begin{array}{l}\text { - Treatment group: Yin Xie Ping Granules, } 4.5 \mathrm{~g} \text { each time, } 2 \text { times daily } \\
\text { - Control group: Xiao Yin Pian Tablets, } 7 \text { tablet each time, } 3 \text { times daily }\end{array}$ \\
\hline Outcomes & $\begin{array}{l}\text { 1. Degree of silvery scales } \\
\text { 2. Red patches } \\
\text { 3. Pruritus } \\
\text { 4. Area of papules }\end{array}$ \\
\hline Notes & Ingredients used in control group Xiao Yin Pian Tablets was not stated \\
\hline \multicolumn{2}{|l|}{ Deng et al. 2010} \\
\hline Methods & $\begin{array}{l}\text { Design: randomised, active comparator-controlled } \\
\text { Duration: } 4 \text { weeks and } 3 \text { months follow-up } \\
\text { Interval of assessment: at } 4 \text { weeks, } 3 \text { months. }\end{array}$ \\
\hline Participants & $\begin{array}{l}\text { Number randomised: } 64 \text { ( } 32 \text { in each group) } \\
\text { Sex (M/F): } 19 / 13 \text { in treatment group and } 22 / 10 \text { in placebo group } \\
\text { Age of participants (mean, rang): } 48.7 \text { (28-62) in treatment group and } 45.6 \text { (24-68) in placebo group } \\
\text { Country and setting: China, single centre } \\
\text { Inclusion criteria of the study } \\
\text { - Diagnostic criteria: clinical diagnosis of psoriasis vulgaris } \\
\text { - Blood-heat syndrome in traditional Chinese medicine } \\
\text { Exclusion criteria of the study } \\
\text { - Severe cardiovascular } \\
\text { - Cerebrovascular } \\
\text { - Prior Acitretin treatment within } 1 \text { months } \\
\text { - Hepatic diseases } \\
\text { - Renal diseases } \\
\text { - Mental disorders } \\
\text { - Women in pregnancy or breastfeeding }\end{array}$ \\
\hline Interventions & $\begin{array}{l}\text { - Treatment group: Xuebijing injection, } 30 \mathrm{ml} \text { daily } \\
\text { - Control group: Acitretin Tablets, } 30 \mathrm{mg} / \mathrm{d}\end{array}$ \\
\hline Outcomes & PASI score \\
\hline
\end{tabular}




\begin{tabular}{|c|c|}
\hline Notes & $\begin{array}{l}\text { Ingredients used in control group Xiao Yin Pian Tablets was not stated. } \\
\text { Concomittent treatment: permitted emollients. }\end{array}$ \\
\hline \multicolumn{2}{|l|}{ Ho et al. 2009} \\
\hline Methods & $\begin{array}{l}\text { Design: randomised, placebo-controlled } \\
\text { Duration: } 6 \text { months } \\
\text { Interval of assessment: every } 2 \text { months } \\
\text { Number randomised: } 61\end{array}$ \\
\hline Participants & $\begin{array}{l}\text { Sex (M/F): } 26 / 22 \text { total ( } 18 / 2 \text { in MTX group, } 14 / 7 \text { in TCM group, } 18 / 2 \text { in placebo group) } \\
\text { Age of participants (mean, range): } 38.45 \text { ( } 21-68) \text { in MTX, } 43.45 \text { (25-80) in TCM, } 43.45 \text { (27-61) in placebo } \\
\text { Country and setting: China, single centre } \\
\text { Inclusion criteria of the study } \\
\text { - Diagnostic criteria: not state } \\
\text { - Psoriatic plaque affect more than } 20 \% \text { of body surface area } \\
\text { - aged more than } 18 \text {-year-old } \\
\text { - Written informed consent } \\
\text { Exclusion criteria of the study } \\
\text { - Renal or liver impairment } \\
\text { - Active infection } \\
\text { - Immunosuppression or other serious concomitant } \\
\text { - Women in pregnancy or breastfeeding } \\
\text { - MTX group: Methotrexate ( } 2.5 \mathrm{mg} / \text { week to } 30 \mathrm{mg} / \text { week), Folic acid } 5 \mathrm{mg} \text { daily }\end{array}$ \\
\hline Interventions & $\begin{array}{l}\text { - TCM group: Wen-tong-hua-yu capsule, dose not stated } \\
\text { - Placebo group: ingredients and dose not stated }\end{array}$ \\
\hline Outcomes & $\begin{array}{l}\text { 1. PASI score } \\
\text { 2. PGA and PDI }\end{array}$ \\
\hline \multicolumn{2}{|l|}{ Li et al. 2008} \\
\hline Methods & $\begin{array}{l}\text { Design: randomised, active comparator-controlled } \\
\text { Duration: } 4 \text { weeks } \\
\text { Interval of assessment: every } 2 \text { weeks }\end{array}$ \\
\hline Participants & $\begin{array}{l}\text { Number randomised: } 58 \\
\text { Sex (M/F): } 37 / 21 \text { total }(19 / 11 \text { in TCM group, } 18 / 10 \text { in placebo group) } \\
\text { Age of participants (mean, range): } 42.16 \pm 11.26 \text { in TCM, } 38.08 \pm 9.64 \text { in placebo } \\
\text { Country and setting: China, single centre } \\
\text { Inclusion criteria of the study } \\
\text { - Diagnostic criteria: Practice guidelines for diagnosis and therapeutic effect evaluation of disease. Peoples's Military Medical Press. 1998. Beijing. China } \\
\text { - Blood-heat syndrome in Traditional Chinese Medicine. Diagnostic and therapeutic effect evaluation criteria for diseases and syndromes of traditional Chinese } \\
\text { medicine. } \\
\text { Nanjing University Press. } 1994 \text {. China } \\
\text { - Aged from } 18 \text { to } 60 \text { years old } \\
\text { - Psoriasis history from } 3 \text { months to } 20 \text { years } \\
\text { Exclusion criteria of the study } \\
\text { - Unknown high fever in previous two months } \\
\text { - Prior systemic immunosuppressants therapy used within three months } \\
\text { - Prior high potent corticosteroid application within three months } \\
\text { - Psoriatic type rather than Psoriasis vulgaris } \\
- \text { Women in pregnancy or breastfeeding }\end{array}$ \\
\hline Interventions & $\begin{array}{l}\text { - Treatment group: Qinzhu Liangxue Decoction, } 30 \mathrm{ml} \text { two times daily. } \\
\text { - Controlled group: Compound Amino-polypeptide Tablets, } 5 \text { tables, three times daily. }\end{array}$ \\
\hline Outcomes & $\begin{array}{l}\text { 1. PASI score (Psoriasis Area and Severity Index) } \\
\text { 2. DLQI score (Dermatology Life Quality Index) } \\
\text { 3. VEGF level (Vascular Endothelial Growth Factor) }\end{array}$ \\
\hline \multicolumn{2}{|l|}{ Notes } \\
\hline \multicolumn{2}{|l|}{ Lone et al. 2011} \\
\hline Methods & $\begin{array}{l}\text { Design: randomised, single-blind, placebo-controlled study } \\
\text { Duration: } 8 \text { weeks } \\
\text { Interval of assessment: fortnightly }\end{array}$ \\
\hline Participants & $\begin{array}{l}\text { Number randomised: } 30 \\
\text { Sex (M/F): } 21 / 9 \text { total ( } 20 \text { in herbal group, } 10 \text { in placebo group) } \\
\text { Age of participants } 11-60 \text { years } \\
\text { Country and setting: India, Bangalore, single centre } \\
\text { Inclusion criteria of the study } \\
\text { - Illness history } \\
\text { - Dermatological examination } \\
\text { - Aged from } 11 \text { to } 60 \text { years old } \\
\text { - Biopsy of the affected area } \\
\text { Exclusion criteria of the study } \\
\text { - Aged blow } 11 \text { years and above } 60 \text { years } \\
\text { - Prior systemic immunosuppressants therapy used within three months } \\
\text { - Unable to give consent } \\
\text { - Psoriasis concomitant with diabetes, vitiligo, dermatophytosis, pityriasis, eczema } \\
\text { - Women in pregnancy or breastfeeding or mentally retarded persons } \\
\text { - Priorlocal or systemic antipsoriatic therapy used within two months }\end{array}$ \\
\hline
\end{tabular}




\begin{tabular}{|c|c|}
\hline Interventions & $\begin{array}{l}\text { - Treatment group: Majoon Ushba } 5 \mathrm{~g} \text { two times daily, Rogbane Hindi } 5-10 \mathrm{ml} \text { topical apply two times daily. } \\
\text { - Controlled group: Wheat flour } 5 \mathrm{~g} \text { two times daily, Coconut oil topical apply two times daily. }\end{array}$ \\
\hline Outcomes & $\begin{array}{l}\text { 1. Itching severity, scaling severity, erythema severity. } \\
\text { 2. PASI score (Psoriasis Area and Severity Index) }\end{array}$ \\
\hline \multicolumn{2}{|l|}{ Notes } \\
\hline \multicolumn{2}{|l|}{ Lu et al. 2012} \\
\hline Methods & $\begin{array}{l}\text { Design: randomised, active comparator-controlled } \\
\text { Duration: } 8 \text { weeks } \\
\text { Interval of assessment: every } 2 \text { weeks }\end{array}$ \\
\hline Participants & $\begin{array}{l}\text { Number randomised: } 84 \\
\text { Sex (M/F): } 61 / 23 \text { total }(28 / 15 \text { in TCM }+ \text { Auricular therapy group, } 33 / 8 \text { in TCM group) } \\
\text { Age of participants (mean, range): } 38.58 \pm 13.13 \text { in TCM + Auricular, } 38.98 \pm 13.80 \text { in TCM } \\
\text { Country and setting: China, single centre } \\
\text { Inclusion criteria of the study } \\
\text { - Diagnostic criteria: Clinical guidelines of Psoriasis } 2008 \text { by Chinese Medical Association China } \\
\text { - Aged from } 18 \text { to } 65 \text { years old } \\
\text { - Sign informed consent. } \\
\text { Exclusion criteria of the study } \\
\text { - Allergic to Yinxieling Formula or the composition of it } \\
\text { - Women in pregnancy or breastfeeding } \\
\text { - Prior oral steroid therapy used within two weeks } \\
\text { - Prior oral retinoid or topical steroid treatment within one week } \\
\text { - Arhropathic, pustular, or erythrodermic psoriasis } \\
\text { - Severe heart, cerebrovascular, live, kidney, hematopoietic system, cancer, psychosis diseases. }\end{array}$ \\
\hline Interventions & $\begin{array}{l}\text { - Treatment group: Auricular + Yinxieling Decoction, } 10 \mathrm{ml} \text { two times daily. } \\
\text { - Controlled group: Yinxieling Decoction, } 10 \mathrm{ml} \text { two times daily. }\end{array}$ \\
\hline Outcomes & $\begin{array}{l}\text { 1. PASI score (Psoriasis Area and Severity Index) } \\
\text { 2. DLQI score (Dermatology Life Quality Index) } \\
\text { 3. VAS (Visual Analogue Scale) } \\
\text { 4. SDS (Self-rating Depression Scale) } \\
\text { 5. SAS (Self-rating Anxiety Scale) }\end{array}$ \\
\hline \multicolumn{2}{|r|}{ 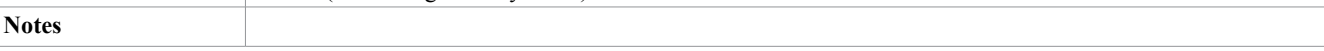 } \\
\hline \multicolumn{2}{|c|}{ Yang et al. 2002} \\
\hline Methods & $\begin{array}{l}\text { Design: randomised, active comparator-controlled } \\
\text { Duration: } 8 \text { weeks } \\
\text { Interval of assessment: before and end of study }\end{array}$ \\
\hline Participants & $\begin{array}{l}\text { Number randomised: } 260 \\
\text { Sex (M/F): } 144 / 116 \text { total }(88 / 72 \text { in treatment group, } 56 / 44 \text { in comparator controlled group) } \\
\text { Age of participants (mean, range): } 30.0 \pm 2.8 \text { in treatment group, } 30.0 \pm 20 \text { in TCM } \\
\text { Country and setting: China, single centre } \\
\text { Inclusion criteria of the study } \\
\text { • Not stated } \\
\text { Exclusion criteria of the study } \\
\text { - Not stated } \\
\text { - Treatment group: LeYin Decoction, } 50 \mathrm{ml} \text { two times daily, and Vitamin E moisturizer application. }\end{array}$ \\
\hline Interventions & - Controlled group: Yinxieling Granule, $10 \mathrm{~g}$ two times daily and Vitamin E moisturizer application. \\
\hline Outcomes & $\begin{array}{l}\text { 1. Therapeutic effect evaluation } \\
\text { 2. Changes of T-cell subsets } \\
\text { 3. Adverse reactions }\end{array}$ \\
\hline \multicolumn{2}{|l|}{ Notes } \\
\hline \multicolumn{2}{|c|}{ Zhang et al. 2009} \\
\hline Methods & $\begin{array}{l}\text { Design: randomised, active comparator-controlled } \\
\text { Duration: } 8 \text { weeks } \\
\text { Interval of assessment: before and at end of week } 8\end{array}$ \\
\hline Participants & $\begin{array}{l}\text { Number randomised: } 80 \\
\text { Sex (M/F): } 74 / 6 \text { total ( } 37 / 2 \text { in TCM+Acitretin, } 37 / 4 \text { in TCM group) } \\
\text { Age of participants (mean, range): } 42.6 \text { in TCM + Auricular, } 43.1 \text { in TCM } \\
\text { Country and setting: China, single centre } \\
\text { Inclusion criteria of the study } \\
\text { - Blood-heat syndrome in Traditional Chinese Medicine Duiding Principles of Clinical } \\
\text { Research on New Drugs of Traditional Chinese Medicine. China } \\
\text { - Diagonosed with psorasis } \\
\text { Exclusion criteria of the study } \\
\text { - Severe photosensitivity } \\
\text { - Women in pregnancy or breastfeeding or planing for pregnancy } \\
\text { - Sensitive to acitretin } \\
\text { - Prior oral acitretin or immunosuppressive therapy within two months } \\
\text { - Complicated with other skin diseases } \\
\text { - Severe heart, cerebrovascular, live, kidney, hematopoietic system, cancer, psychosis diseases. }\end{array}$ \\
\hline Interventions & $\begin{array}{l}\text { - Treatment group: TCM decoction + Qingkailing Injection } 40 \mathrm{ml} \text { daily + Acitretin } 20-30 \mathrm{mg} \text { daily } \\
\text { - Controlled group: TCM decoction + Qingkailing Injection } 40 \mathrm{ml} \text { daily }\end{array}$ \\
\hline Outcomes & 1. PASI score (Psoriasis Area and Severity Index) \\
\hline
\end{tabular}


Lone et al. [48]) overlap 1, the $95 \%$ confidence intervals of the study (Ahmadi et al. [43]) do not overlap 1. There is statistical significance at the meta-analysis level. The herbal intervention is better than control as the overall effect estimate and its $95 \%$ confidence intervals are to the right of the line of no treatment effect. The total number of participants in the herbal intervention groups is 48 and the control group is 41 .

The heterogeneity test is shown at the bottom of the Figure 2 on the left hand side, the number of interest is the $\mathrm{I}^{2}$ value. $\mathrm{I}^{2}$ was developed and introduced as the preferable and more reliable test for heterogeneity (Higgins et al. [52]). $\mathrm{I}^{2}$ ranges between 0 and 100\%, the values of $\mathrm{I}^{2}$ equal to $25 \%, 50 \%$, and $75 \%$ representing low, moderate, and high heterogeneity, respectively. Heterogeneity measures the variability between studies, in other words it gives an indication how comparable studies in the meta-analysis are. A useful visual guide to assess heterogeneity is to check the overlap of the CIs, i.e. the horizontal lines in the meta-analysis graph. Studies are regarded as homogeneous if CIs of all studies overlap. The heterogeneity of this subgroup studies are moderate $\left(\mathrm{I}^{2}=68\right)$. The test for overall effect is statistical significance with the probability value $(\mathrm{p}=0.01)$.

Four studies, Chang et al. [44], Deng et al. [45], Ho et al. [46] Li et al. [47], included in the subgroup B meta-analysis (Figure 3). The total number of participants in the herbal intervention groups is 136 and the competitor group is 139. The mean effect estimate for 3 studies Deng et al. [45], Ho et al. [46], Li et al. [47] which using herbal intervention compare with western drug treatment favours western drug treatment.
The $95 \%$ confidence intervals of Ho et al. [46] study are to the left of the line of no treatment effect that show the MTX is superior than the herbal intervention. Chang et al. [44] used competitive herbal medicine to compare with investigative herbal medicine, the mean effect estimate favours herbal intervention, but the $95 \%$ confidence intervals overlap 1. On the forest plot shown on Figure 3, the competitor is better than herbal intervention as the overall effect estimate and its $95 \%$ confidence intervals are to the left of the line of no treatment effect. The heterogeneity of this subgroup studies are moderate $\left(\mathrm{I}^{2}=52\right)$. The test for overall effect is statistical significance with the probability value $(\mathrm{p}=0.03)$.There is statistical significance at the meta-analysis level.

Two studies, Lu et al. [49] and Zhang et al. [51] included in the subgroup C meta-analysis (Figure 4). The total number of participants in the herbal intervention groups is 82 and the herbal combine other medication group is 81 . The mean effect estimates for these two studies favours herbal medicine in combination with Auricular acupuncture or western medicine Acitretin group. The $95 \%$ confidence intervals of Lu et al. [49] study are to the right of the line of no treatment effect that show the herbal combing with Auricular therapy is superior than the herbal intervention alone. Zhang et al. [51] used herbal medicine combine with Acitretin to compare with herbal medicine alone, the mean effect estimate favours herbal combination therapy, but the $95 \%$ confidence intervals overlap 1. On the forest plot shown on Figure 4, the competitor is better than herbal intervention as the overall effect estimate and its $95 \%$ confidence intervals are to the right of the line of no treatment effect. The heterogeneity of this subgroup studies are

\begin{tabular}{|c|c|c|c|c|c|c|c|c|}
\hline Study or Subgroup & \multicolumn{2}{|c|}{ Herbal } & \multicolumn{2}{|c|}{ Placebo } & Weight & $\begin{array}{l}\text { Risk Ratio } \\
\text { M-H, Fixed, } 95 \% \mathrm{Cl}\end{array}$ & \multicolumn{2}{|c|}{$\begin{array}{c}\text { Risk Ratio } \\
\text { M-H, Fixed, 95\% Cl }\end{array}$} \\
\hline Ahmadi et al 2008 & 9 & 14 & 0 & 14 & $11.5 \%$ & $19.00[1.21,297.89]$ & & \\
\hline Ho et al 2009 & 0 & 14 & 3 & 17 & $73.3 \%$ & $0.17[0.01,3.06]$ & & \\
\hline Lone et al 2011 & 10 & 20 & 0 & 10 & $15.1 \%$ & $11.00[0.71,170.64]$ & & \\
\hline Total $(95 \% \mathrm{CI})$ & & 48 & & 41 & $100.0 \%$ & $3.98[1.36,11.62]$ & & \\
\hline Total events & 19 & & 3 & & & & & \\
\hline $\begin{array}{l}\text { Heterogeneity: } \mathrm{Chi}^{2}= \\
\text { Test for overall effec }\end{array}$ & $\begin{array}{l}6.34, \mathrm{df} \\
Z=2.53\end{array}$ & $\begin{aligned}= & 2(P \\
& (P=0\end{aligned}$ & $\begin{array}{l}=0.04) \text {; } \\
.01)\end{array}$ & $I^{2}=68$ & & & $\begin{array}{ll}0.01 & 0.1 \\
\text { Favours Placebo }\end{array}$ & $\begin{array}{c}10 \quad 100 \\
\text { Favours Herbal }\end{array}$ \\
\hline
\end{tabular}

Figure 2. Subgroup A. Meta-analysis of Effective Rate of Herbal vs. Placebo (CI: confidence interval, $M$ - $H$ : Mantel-Haenszel).

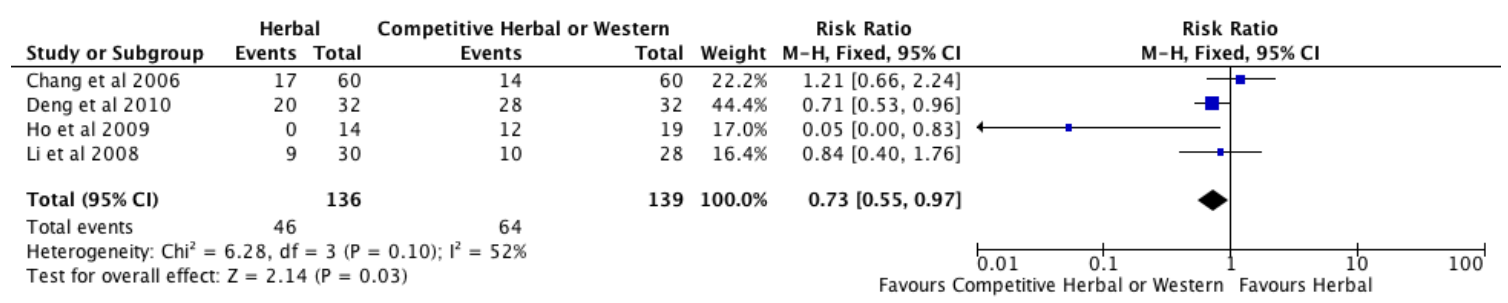

Figure 3. Subgroup B. Meta-analysis of Effective Rate of Herbal vs. Competitor (herbal or western drug) (CI: confidence interval, $M$ - $H$ : Mantel-Haenszel).

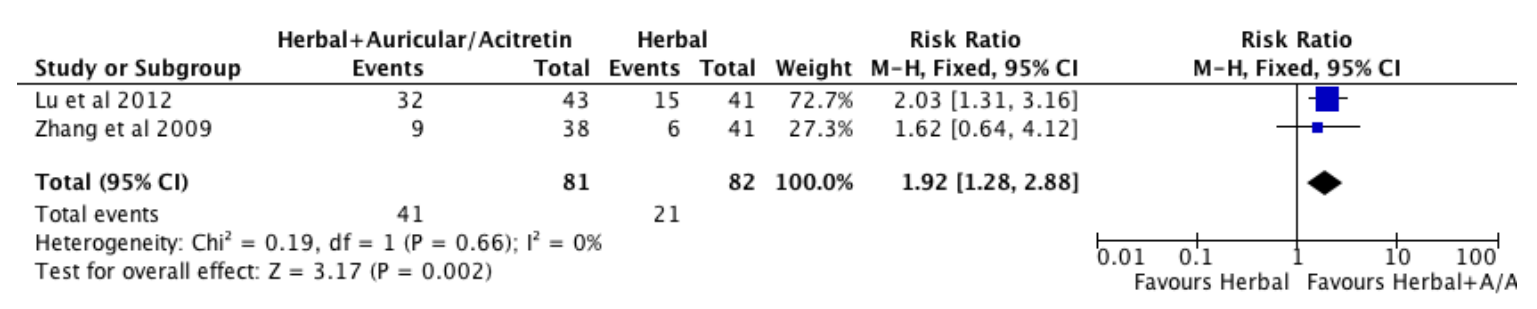

Figure 4. Subgroup C. Meta-analysis of Effective Rate of Herbal + other medication vs. Herbal Alone (CI: confidence interval, $M$ - $H$ : Mantel-Haenszel). 


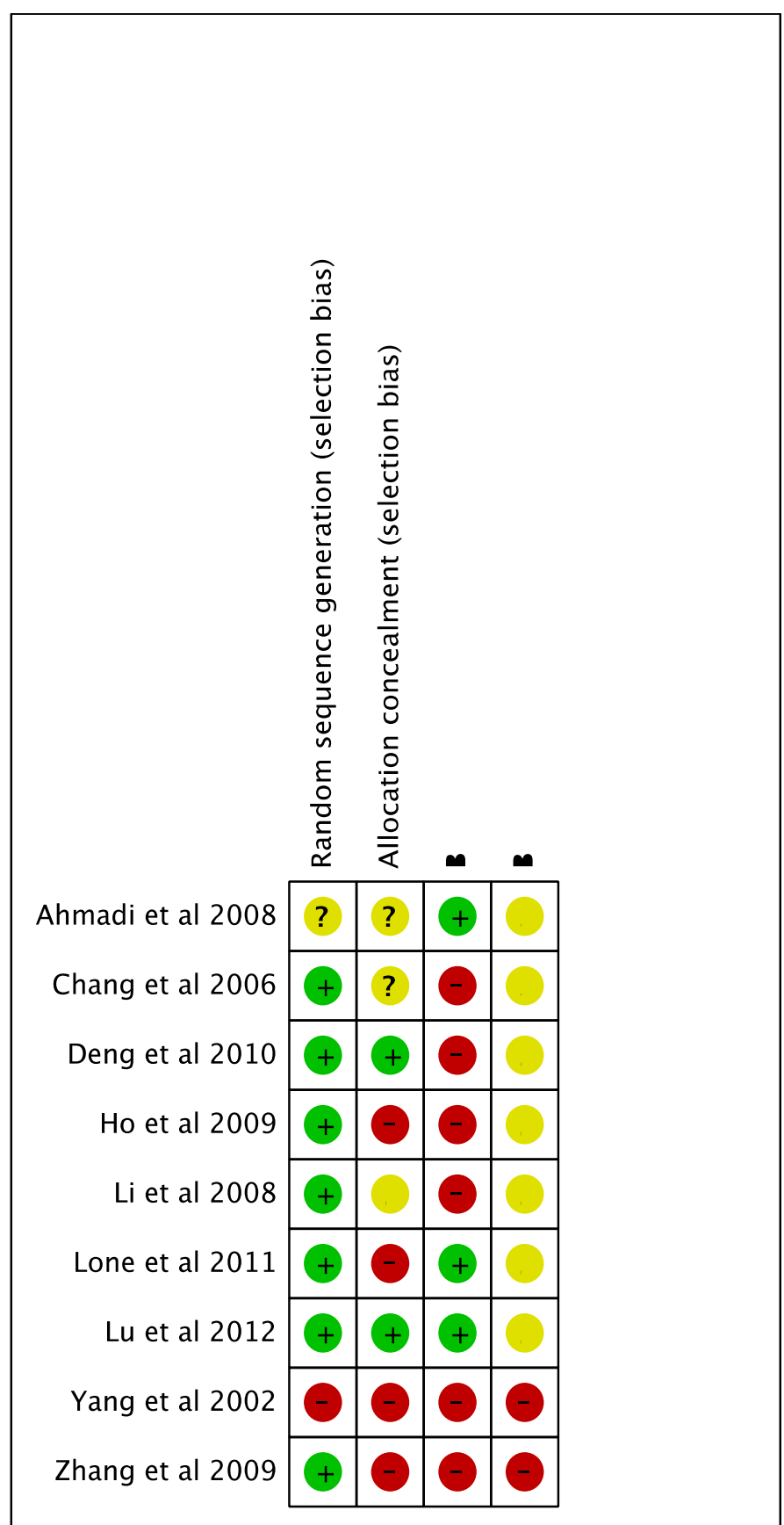

Figure 5. Summary of risk of bias assessment.

(+: Low Risk, -: High Risk, ?:Unclear)

low $\left(\mathrm{I}^{2}=0\right)$. The test for overall effect is statistical significance with the probability value $(\mathrm{p}=0.002)$. There is statistical significance at the metaanalysis level.

\section{Synthesis and interpretation}

In total, 9 RCTs [43-52] were included in the qualitative synthesis (Table 2) and 9 RCTs [43-52] were included in the meta-analysis (Figures 2-4). Regarding the effectiveness of herbal medication for psoriasis, 3 RCTs revealed that herbal medicine performed better than placebo control, 3 RCTs showed that the western drug competitor is superior than herbal intervention, 1 RCT showed the herbal medicine performed better than competitive herbal medicine, 2 RCTs suggested that herbal combined with other medication (Auricular or Acitretin) is better than herbal medicine alone. Regarding adverse reactions, the abnormal liver function were reported in 8 participants in Acitretin (western drug) group (Deng et al.) [45], the results of Zhang et al. [51] indicated that herbal medicine reduce the occurrence of adverse reaction of western medicine Acitretin when it is used combine with herbal medicine. The adverse events were reported by $65 \%$ in the MTX (western drug) group, $48 \%$ in the herbal intervention group and $30 \%$ in the placebo group (Ho et al.) [46].

This review showed no significant safety concerns regarding systemic herbal medication for psoriasis. But in these 9 studies, herbal medicine was only administered for 4 weeks to 6 months under controlled conditions. The included studies used different methods of medication delivery: 4 studies [47,49-51] used decoctions, 1 used powder (Lone et al.[48]), 1 used tablet (Ahmadi et al. [43]), 2 used capsule (Hagazi et al. [52], Ho et al. [46]), 1 used granules (Chang et al. [44]) and 1 used injection (Deng et al. [45]). It remains unclear if the different methods of herbal medicine delivery influence their treatment effects [53,54].

\section{Quality evaluation on the evidence}

The risk of bias assessment is conducted by using the Cochrane Collaboration's tool for assessing risk of bias [41]. The overall risk of assessment found that the quality of studies was poor (Figure 5), therefore the results from the meta-analysis have to be translated with caution. None of 9 RCTs was judged with "Low Risk" in all domains for bias assessment. All 9studies had "High Risk" or "Unclear" judgements in $\geq 2$ domains (Figure 5).

7 RCTs (Ahmadi et al. [43], Chang et al. [44], Ho et al. [46], Li et al. [47], Lone et al. [48], Yang et al. [50], Zhang et al. [51]) did not state the method used to conceal the allocation sequence, hence selection bias may occurred due to inadequate concealment of allocations prior to assignment.

6 RCTs (Chang et al. [44], Deng et al. [45], Ho et al. [46], Li et al. [47], Yang et al. [50], Zhang et al. [51]) failed to blind study participants and personnel from knowledge of which intervention a participant received. The granules were used as intervention and tablets were used as control (Chang et al. [44]). The herbal injection was used as intervention and tablets used as control (Deng et al. [45]). Capsules were used as intervention, tablets were used as competitor, placebos were used as control, but investigators did notdescribe the details on the chemical properties of the herbal placebo (Ho et al. [46]). The decoctions were used as intervention and tablet were used as control (Li et al. [47]). The decoctions were used as intervention and granule were used as control (Yang et al. [50]). The decoction combined with injection and tablet used as intervention and decoction plus injection used as control (Zhang et al. [51]). Therefore the performance bias may incur due to knowledge of the allocated interventions by participants and personnel during these studies.

The detection bias is high risk in all 9 RCTs because none of these studies describe measures used to blind outcome assessors from knowledge of which intervention a participant received and provide any information relating to whether the intended blinding was effective.

The quality of reporting is evaluated by using the CONSORT framework [40] to check if the adequate important aspects of research information are included in reports of controlled clinical trials of 


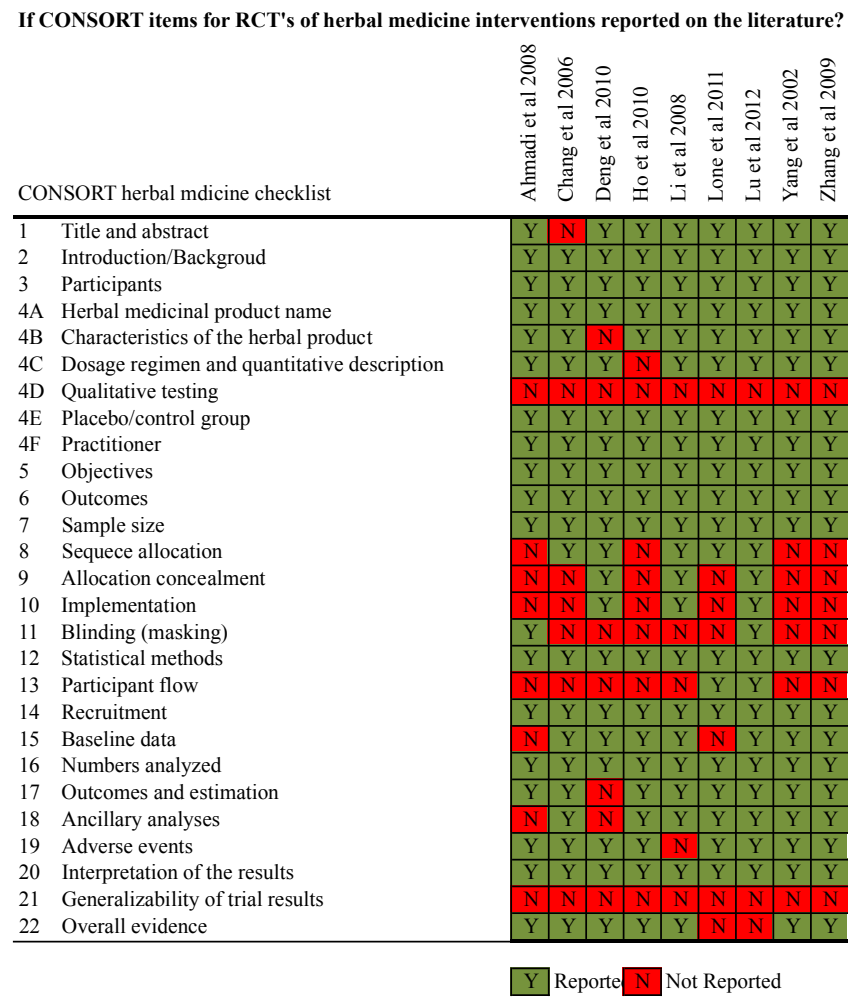

Figure 6. Summary of CONSORT 22 items for RCTs of herbal medicine.

herbal interventions. The 22-item checklist of the CONSORT for herbal intervention is compiled on Figure 6.

None of 9 RCTs report the item 4D (Qualitative Testing) (Figure 6) investigational product's chemical fingerprint and methods used and which laboratory performed them. Herbal medicines are often contaminated [55], thus a complete description of any special testing or purity testing (e.g. heavy metal test) and the removal of unwanted components should be included in reports.

Only two RTCs (Ahmadi et al. [43], Lone et al. [48]) reported blinding item 11 (Blinding) (Figure 6). Ahmadi et al. [43] state the trials as "double-blind", but did not give the details on the properties of the herbal placebo. Lone et al. [48] state the trails as "single blind" and specified wheat flour serviced as control to compare with investigational herbal "Majoon Ushba". However these 2 RCTs did not state whether those investigators administering the intervention and those assessing the outcomes were blinded, how the success of blinding of participant was evaluated.

None of 9 RCTs report the external validity of trial result item 12 (Generalizability) (Figure 6). Generalizability is the extent to which the results of a study hold true in other individuals or groups, other similar interventions, dosages, timing, administration routes and other settings [40]. The herbal medicinal products are available widely on the market with variable quality and ingredients, how the products used in the RCTs relate to what is available and used by consumers and health care practitioners is quite valuable information which enable reader to understand products that may act similarly to the one used in the trial.

The 9 included RCTs reported adequate information on Title and Abstract section (item 1) and Introduction section (item 2), showed the minor issue on reporting Result section (item 13-19) and
Discussion section (item 20-22) as item 13 (Participant Flow) and item 21 (Generalizability) are uncompleted reported, and showed the nonadequate reporting in Methods section (item 3-12) because the item 4D (Qualitative Testing), item 8 (Sequence Allocation), item 9 (Allocation Concealment), item 10 (Implementation) and item 11 (Blinding) are poorly reported lacked with details. Such findings on checklist of the CONSORT for herbal intervention (Figure 6) are also corresponded with the risk of bias assessment (Figure 5).

\section{Discussion}

This review did not include unpublished studies, case reports, caseseries, or retrospective studies, non-English studies. The reviewers are aware of the high possibility of publication bias due to exclusion of non-English language publication in this review. The exclusion of Chinese language articles may result in partial estimate of intervention effect for herbal interventions [56].

Only 9 small inadequate reported RCTs with short study duration were available for assessment. None was effectively blinded. Although blinding presents practical difficulties when herbal decoctions are used, without blinding it is impossible to conclude that the benefit observed was due to herbal medicine alone. The evidence is inconclusive due to the high risk of bias of the included trials and the limited number of trials with each of herbal medication formulas, as well as the limited number of included participants and patient relevant outcomes. Hence the author cannot be certain of the effectiveness and safety of the studies in this review of herbal medicines for the treatment of psoriasis.

To obtain a high level of evidence on herbal medicines on psoriasis treatment and to give guidance on clinical practice, more international, multicentre, rigorously designed, high-quality trials with large sample sizes are required. Attention should be paid to the sample size estimation, the definition of outcomes, duration of treatment and follow-up, and the reporting of adverse events. In addition, the following methodological issues should be addressed: the trial design should be according to the SPIRIT Statement (www.spirit-statement. org), including the methods of randomisation and blinding with the use of placebo with the same appearance, taste, and smell, and reporting trials according to the CONSORT statement for herbal intervention (www.consort-statement.org). To improve the quality of future trials, the author suggest that all researchers receive the necessary training on clinical trial methodology before designing a trial and register the trial on an internationally recognised public trial registry. From the results of this review, the detailed description of the pharmacology of the interventions and clinical outcomes should be emphasised for herbal medicines. Information about species, geographical origin of herbs, season for collecting the herbs, and quality of the preparations should be provided [40].

3 RCTs (Figure 2) revealed that herbal medicine performed better than placebo control $\left(\mathrm{RR}=3.98,1.36-11.62,95 \% \mathrm{CI}, \mathrm{I}^{2}=68 \%\right.$, $\mathrm{p}=0.01)$, but results were heterogeneous $\left(\mathrm{I}^{2}>50 \%\right) .4$ RCTs (Figure 3) showed that the western drug competitor is superior than herbal intervention $\left(\mathrm{RR}=0.73,0.53-0.97,95 \% \mathrm{CI}, \mathrm{I}^{2}=52 \%, \mathrm{p}=0.03\right)$, but results were heterogeneous $\left(\mathrm{I}^{2}>50 \%\right) .2$ RCTs (Figure 4$)$ suggested that herbal medicine combined with other medication (Auricular or Acitretin) is more effective than herbal medicine alone $(\mathrm{RR}=1.92,1.28-2.88,95 \% \mathrm{CI}$, $\mathrm{I}^{2}=0 \%, \mathrm{p}=0.002$ ), but these results need to be interpreted with caution due to methodological weaknesses and the lack of replicated studies. The results of 1 RCT (Zhang et al. [51]) indicated that herbal medicine reduce the occurrence of adverse reaction of western medicine Acitretin when it is used combine with herbal medicine. We found no significant 
difference on adverse effects between herbal medicine and placebo control groups. However, the findings are not conclusive due to the high risk of bias of the included trials and the limited number of trials testing individual herbal medicines. All the studies had small sample size that can decrease the chances of finding a positive effect if one truly exists, moreover most of the studies had short study duration from 4 weeks to 8 weeks which can hide potential undetectable long-term side effect of investigational herbal medicine if one truly exists. In reviewers' opinion, it is premature to recommend any of these herbal medicines to psoriasis patients. Therefore there is clearly a need for well-designed and larger scalerigorous randomized controlled trials with CONSORT reporting format to determine the safety and efficacy of these herbal interventions.

\section{References}

1. Menter A Gottlieb A, Feldman SR, Van Voorhees AS, Leonardi CL, et al. (2008) Guidelines of care for the management of psoriasis and psoriatic arthritis: Section 1. Overview of psoriasis and guidelines of care for the treatment of psoriasis with biologics. J Am Acad Dermatol 58: 826-850. [Crossref]

2. Kurd SK Gelfand JM (2009) The prevalence of previously diagnosed and undiagnosed psoriasis in US adults: results from NHANES 2003-2004. J Am Acad Dermatol 60: 218-224. [Crossref]

3. Nestle FO Kaplan DH, Barker J (2009) Psoriasis. N Engl J Med 361: 496-509. [Crossref]

4. Naldi L (2004) Epidemiology of psoriasis. Curr Drug Targets Inflamm Allergy 3: 121128. [Crossref]

5. Gelfand JM Weinstein R, Porter SB, Neimann AL, Berlin JA, et al. (2005) Prevalence and treatment of psoriasis in the United Kingdom: a population-based study. Arch Dermatol 141: 1537-1541. [Crossref]

6. Mason A Mason J, Cork M, Hancock H, Dooley G (2013) Topical treatments for chronic plaque psoriasis: an abridged Cochrane systematic review. J Am Acad Dermatol 69: 799-807. [Crossref]

7. Shao CG (1996) The prevalence, prevention and treatment of psoriasis in China. Chin J Dermatol 29: 75-76.

8. Javitz HS Ward MM, Farber E, Nail L, Vallow SG (2002) The direct cost of care for psoriasis and psoriatic arthritis in the United States. J Am Acad Dermatol 46: 850-860. [Crossref]

9. de Korte J Sprangers MA, Mombers FM, Bos JD (2004) Quality of life in patients with psoriasis: a systematic literature review. J Investig Dermatol Symp Proc 9: 140-147. [Crossref]

10. Neiman AN, Porter S, Gelfand JM (2006) The epidemiology of psoriasis. Expert Rev Dermatol 1: 63-75.

11. Fowler JF Duh MS, Rovba L, Buteau S, Pinheiro L, et al. (2008) The impact of psoriasis on health care costs and patient work loss. J Am Acad Dermatol 59: 772-780. [Crossref]

12. Yu AP Tang J, Xie J, Wu EQ, Gupta SR, et al. (2009) Economic burden of psoriasis compared to the general population and stratified by disease severity. Curr Med Res Opin 25: 2429-2438. [Crossref]

13. Stern RS Nijsten T, Feldman SR, Margolis DJ, Rolstad T (2004) Psoriasis is common, carries a substantial burden even when not extensive, and is associated with widespread treatment dissatisfaction. J Investig Dermatol Symp Proc 9: 136-139. [Crossref]

14. Gudjonsson JE, Elder JT (2012) Psoriasis. In: Fitzpatrick's Dermatology in General Medicine. (8thedtn). McGraw-Hill Medical, New York, USA.

15. Bonifati C Carducci M, Mussi A, D'Auria L, Ameglio F (1998) Recognition and treatment of psoriasis. Special considerations in elderly patients. Drugs Aging 12: 177190. [Crossref]

16. Griffiths CE (2004) Psoriasis: future research needs and goals for the twenty-first century. Dermatol Clin 22: 493-499. [Crossref]

17. Lebwohl M (2005) A clinician's paradigm in the treatment of psoriasis. J Am Acad Dermatol 53: S59-69. [Crossref]

18. Capasso L (1998) 5300 years ago, the Ice Man used natural laxatives and antibiotics. Lancet 352: 1864. [Crossref]
19. Wilt TJ Ishani A, Stark G, MacDonald R, Lau J, et al. (1998) Saw palmetto extracts for treatment of benign prostatic hyperplasia: a systematic review. JAMA 280: 1604-1609. [Crossref]

20. Kaptchuk TJ (2002) Acupuncture: theory, efficacy, and practice. Ann Intern Med 136: 374-383. [Crossref]

21. Blumenthal M (2003) The ABC Clinical Guide to Herbs. American Botanical Council. Thieme, New York, USA.

22. Vickers A, Zollman C (1999) ABC of complementary medicine: herbal medicine. BMJ 319: 1050-1053. [Crossref]

23. Linde K ter Riet G, Hondras M, Vickers A, Saller R, et al. (2001) Systematic reviews of complementary therapies - an annotated bibliography. Part 2: herbal medicine. BMC Complement Altern Med 1: 5. [Crossref]

24. Jensen P (1990) Use of alternative medicine by patients with atopic dermatitis and psoriasis. Acta Derm Venereol 70: 421-424. [Crossref]

25. Fleischer AB Jr Feldman SR, Rapp SR, Reboussin DM, Exum ML, et al. (1996) Alternative therapies commonly used within a population of patients with psoriasis Cutis 58: 216-220. [Crossref]

26. Clark CM, Mckay RA, Fortune DG, Griffiths CE (1998) Use of alternative treatments by patients with psoriasis. Br J Gen Pract 48: 1873-1874. [Crossref]

27. Ben-Arye E Ziv M, Frenkel M, Lavi I, Rosenman D (2003) Complementary medicine and psoriasis: linking the patient's outlook with evidence-based medicine. Dermatology 207: 302-307. [Crossref]

28. Chen YF Chang JS (2003) Complementary and alternative medicine use among patients attending a hospital dermatology clinic in Taiwan. Int J Dermatol 42: 616-621. [Crossref]

29. Baron SE Goodwin RG, Nicolau N, Blackford S, Goulden V (2005) Use of complementary medicine among outpatients with dermatologic conditions within Yorkshire and South Wales, United Kingdom. J Am Acad Dermatol 52: 589-594. [Crossref]

30. Prieto JM Recio MC, Giner RM, Máñez S, Giner-Larza EM, et al. (2003) Influence of traditional Chinese anti-inflammatory medicinal plants on leukocyte and platelet functions. J Pharm Pharmacol 55: 1275-1282. [Crossref]

31. Bernstein S Donsky H, Gulliver W, Hamilton D, Nobel S, et al. (2006) Treatment of mild to moderate psoriasis with Reliéva, a Mahonia aquifolium extract--a double-blind, placebo-controlled study. Am J Ther 13: 121-126. [Crossref]

32. Smith N Weymann A, Tausk FA, Gelfand JM (2009) Complementary and alternative medicine for psoriasis: a qualitative review of the clinical trial literature. $J$ Am Acad Dermatol 61: 841-856. [Crossref]

33. Song P Lysvand H, Yuhe Y, Liu W, Iversen OJ (2010) Expression of the psoriasisassociated antigen, Pso p27, is inhibited by traditional Chinese medicine. $J$ Ethnopharmacol 127: 171-174. [Crossref]

34. Capella GL Finzi AF (2003) Complementary therapy for psoriasis. Dermatol Ther 16 164-174. [Crossref]

35. Deng S May BH, Zhang AL, Lu C, Xue CC (2013) Topical herbal medicine combined with pharmacotherapy for psoriasis: a systematic review and meta-analysis. Arch Dermatol Res 305: 179-189. [Crossref]

36. May BH Zhang AL, Zhou W, Lu CJ, Deng S, et al. (2012) Oral herbal medicines for psoriasis: a review of clinical studies. Chin J Integr Med 18: 172-178. [Crossref]

37. Richardson WS, Wilson MC, Nishikawa J, Hayward RS (1995) The well built clinical question: a key to evidence-based decisions. ACP J Club 123: A12-13. [Crossref]

38. Dickersin K Scherer R, Lefebvre C (1994) Identifying relevant studies for systematic reviews. BMJ 309: 1286-1291. [Crossref]

39. Begg C Cho M, Eastwood S, Horton R, Moher D, et al. (1996) Improving the quality of reporting of randomized controlled trials. The CONSORT statement. JAMA 276: 637-639. [Crossref]

40. Gagnier JJ Boon H, Rochon P, Moher D, Barnes J, et al. (2006) Reporting randomized, controlled trials of herbal interventions: an elaborated CONSORT statement. Ann Intern Med 144: 364-367. [Crossref]

41. Higgins JP Altman DG, Gøtzsche PC, Jüni P, Moher D, et al. (2011) The Cochrane Collaboration's tool for assessing risk of bias in randomised trials. BMJ 343: d5928. [Crossref] 
42. Liberati A, Altman DG, Tetzlaff J, Mulrow C, Gøtzsche PC, et al. (2009) The PRISMA statement for reporting systematic reviews and meta-analyses of studies that evaluate health care interventions: explanation and elaboration. PLoS Medicine 6: e1000100.

43. Ahmadi A Barikbin B, Naseri M, Mohagheghi M (2008) The effect of HESA-A on psoriasis vulgaris. J Drugs Dermatol 7: 559-561. [Crossref]

44. Shan C Yuan L, Xiuzhen B, Aiju Q (2006) Treatment of psoriasis vulgaris by ora administration of yin xie ping granules--a clinical report of 60 cases. J Tradit Chin Med 26: 198-201. [Crossref]

45. Deng JQ Liu QP, Fan RQ (2010) Clinical observation of Xuebijing injection for the treatment of psoriasis vulgaris. Nan Fang Yi Ke Da Xue Xue Bao 30: 2772-2773. [Crossref]

46. Ho SG Yeung CK, Chan HH (2010) Methotrexate versus traditional Chinese medicine in psoriasis: a randomized, placebo-controlled trial to determine efficacy, safety and quality of life. Clin Exp Dermatol 35: 717-722. [Crossref]

47. Li FL Li B, Xu R, Song X, Yu Y, et al. (2008) Qinzhu Liangxue Decoction in treatment of blood-heat type psoriasis vulgaris: a randomized controlled trial. Zhong Xi Yi Jie He Хиe Bao 6: 586-590. [Crossref]

48. Lone AH Ahmad T, Naiyar AH (2011) Clinical evaluation of efficacy of Majoon Ushba and Roghane Hindi in the management of psoriasis: A randomized single-blind, placebo-controlled study. J Ayurveda Integr Med 2: 26-31. [Crossref]

49. Lu CJ, Xiang Y, Xie XL, Xuan ML, He ZH (2012) A randomized controlled single-blind clinical trial on 84 outpatients with psoriasis vulgaris by auricular therapy combined with optimized Yinxieling Formula. Chin J Integr Med 18: 186-191. [Crossref]

50. Yang HP, Hu RJ, Qi Y, Xu LM, Qiao SF (2002) Clinical and experimental study on treatment of Psoriasis Maculata by Leyin. Chin J Integr Trad West Med 8: 256-261.

51. Zhang LX Bai YP, Song PH, You LP, Yang DQ (2009) Effect of Chinese herbal medicine combined with acitretin capsule in treating psoriasis of blood-heat syndrome type. Chin J Integr Med 15: 141-144. [Crossref]

52. Hegazi AG, Abd Raboh FA, Ramzy NE, Shaaban DM, Khader DY (2013) Bee venom and propolis as new treatment modality in patients with localized plaque psoriases. Int Res J Med Med Med Sci 1: 27-33.

53. Li SL, Song JZ, Qiao CF, Zhou Y, Xu HX (2010) UPLC-PDA-TOFMS based chemical profiling approach to rapidly evaluate chemical consistency between traditional and dispensing granule decoctions of traditional medicine combinatorial formulae. J Pharm Biomed Anal 52: 468-478. [Crossref]

54. Luo H Li Q, Flower A, Lewith G, Liu J (2012) Comparison of effectiveness and safety between granules and decoction of Chinese herbal medicine: a systematic review of randomized clinical trials. J Ethnopharmacol 140: 555-567. [Crossref]

55. Chan K (2003) Some aspects of toxic contaminants in herbal medicines. Chemosphere 52: 1361-1371. [Crossref]

56. Moher D Pham B, Lawson ML, Klassen TP (2003) The inclusion of reports of randomised trials published in languages other than English in systematic reviews. Health Technol Assess 7: 1-90. [Crossref]

Copyright: (C2015 Tang TY. This is an open-access article distributed under the terms of the Creative Commons Attribution License, which permits unrestricted use, distribution, and reproduction in any medium, provided the original author and source are credited. 